\title{
Satisfaction, Perceived Usability and Trust Impact on Website Trustworthiness
}

\author{
Rakesh Kumar \\ Faculty of Compute Science \\ Institute of Business \\ Administration, Karachi, Pakistan
}

\author{
Afshan Ejaz \\ Faculty of Compute Science \\ Institute of Business \\ Administration, Karachi, Pakistan
}

\author{
Syed Asim Ali \\ Department of Compute Science \\ University of Karachi, Karachi, \\ Pakistan
}

\begin{abstract}
Excessive use of Internet has transformed the way business activities are conducted as consequences consumer trustworthiness and consumer satisfaction got a new urge.Some researchers have proved that consumer's satisfaction can solely be achieved by usability Moreover, It is also suggested that usability can be beneficial to improve trust levels because the ease of use of a system extends more understanding and a greater capacity to infer how the system will act. Thus, usability may improve trust levels as well.This research study focuses on the aspects that influence the customer trustworthiness for a website. 5 hypotheses are designed and a research survey is conducted to test the hypothesis.
\end{abstract}

\section{General terms}

Human Computer Interaction, Software Engineering

\section{Keywords}

Perceived Usability, Satisfaction, Trust, Trustworthiness

\section{INTRODUCTION}

Excessive use of Internet have transformed the way business activities are conducted [1], Industries like E-commerce have evolved from phone calls to fax machines and now Ecommerce is heavily relying on internet [2] and as a consequences consumer loyalty and consumer satisfaction got a new urge. Consumer loyalty is a major concern for EBusinesses and it can only be achieved by satisfying our consumers; satisfaction can be originated from consumer trust [3]. Consumer trust and Usability of the websites are getting importance because they are playing their part in providing the services using internet, few studies have been done to analyze the relationship between them [4].Our study focuses on the influence of perceived website usability on user trust and satisfaction and the incidence of these three variables on the loyalty shown by Internet users.

\section{USABILITY}

Users are anticipated to get benefited more from the easiness and accessibility of E-shopping compared to that of older way, though online shopping from its nature seems distant as compare to outdated ways, it provides some new and really interesting possibilities as well [5] .There are many research studies conducted to analyze the consumer perceptions about these formations [5] and about the effect of websites' attributes on potential consumers [4]. On the basis of those studies it can be seen that in modern era Perceived Website Usability - PWD plays an essential role in making a better image for a store or a Business. In fact when an organization is based on internet, usability becomes a key factor [6]. Some researchers have proved that consumer's satisfaction can solely be achieved by usability and also usability is considered as one of the key dimensions of website's overall quality [7] [8].

According to ISO 9241-11 Usability guidance, Usability is "Extent to which a product can be used by specified users to achieve specified goals with effectiveness, efficiency and satisfaction in a specified context to use" [9]. Usability reveals Perceived ease when we are navigating on the site or when we are making any purchase using internet. According to Nielson, usability of a website encompasses the effortlessness to learn a new software product and to remember its functionality, the extent of avoiding the error, the effectiveness of design of a software product, and the overall pleasure felt by the user [10].

\section{LITERATURE REVIEW AND HYPOTHESIS:}

\subsection{Trust:}

Trust can be well-defined as a series of positive opinions detained by someone resulting from ones perceptions about certain characteristics [11], this set of positive views has been distributed into dissimilar dimensions and often trust is measured as a multidimensional concept that distinguishes the honesty and benevolence perceived in the conduct of the other party.

Honesty can be described as; to believe that other party will fulfill promises that he/she has made and will be sincere [12] Benevolence can be explained as; to believe that one of the persons is intended to benefit the other person without aiming for any opportunistic behavior and encourages a bilateral favorable relationship [13] [14]. Many practitioners have emphasized on the additional dimensions of trust as well for instance, in the perceived competence of the other person [15].

It has concern with the capability and perceived dexterity possessed by the other person [16]. Explicitly, competence is the measure by which consumer recognizes that seller has the expertise and understanding to fulfill a promise or any sort of exchange, perceived competence is particularly appropriate when we want to analyze customer's Internet behavior. Absence of necessary knowledge about a relationship can have an unfavorable effect on the process [17]. Newly formed business, lack of confidence and insecurity about digital payments, unease about order handling or conditions of product delivery are few important factors those gratify the sellers to demonstrate that their website has technical, monetary, and H.R needed to fulfill the rules and regulations of the trade contract. Therefore trust is considered as a concept formed by these three dimensions: honesty, benevolence and competence perceived in a website.Few Researchers have evaluated the importance of trust in online 
relationships by distinguishing different stages, initially, when a customer visits a website, he has to overcome an "exploratory phase" before being ready to perform any purchase. In this exploration stage, the new customers have no prior knowledge and consequently trust is based on few important aspects such as brand image or individuals' opinion that can be in the form of testimonial.

When the customer is done with this first phase, the customer will decide if he wants to perform any transaction, this phase is called "commitment phase". It is the individual's interaction and experience with the online platform that regulates the intensity of trust [4]. Our research deals with second phase, people who participated in our survey have already experienced the usage of websites; these experiences allow customers to decide whether to stay with the website or to move to another platform. Thus, trust can be produced after enough knowledge is accumulated.

A very few authors have emphasized on the importance of trust in Internet relations. When a consumer is performing any online transaction for shopping, uncertainty or insecure nature of the consumer is major hindrance in the growth of $\mathrm{E}$ business [18].

It is suggested that usability can be beneficial to improve trust levels because the ease of use of a system extends more understanding and a greater capacity to infer how the system will act. Thus, usability may improve trust levels [19]. Based on such statements we state hypotheses:

H1: The degree of trust directly and positively impact the website usability

\subsection{Satisfaction:}

Satisfaction can be defined as an affective customer condition that could be a result of a comprehensive evaluation of various features that build up the customer relationship [20]. Satisfaction can be buildup following same process as trust does.Satisfaction basically is a representation of a positive attitude of a costumer. Satisfaction is a reaction to the consistent service provision of a company and its friendly behavior towards its customers. In every transaction, customer's insight is nourished by some fresh information. A very few research studies have been initiated to study about the factors that impact consumer satisfaction [21]. Some research works highlight the impact of website design on the degree of Internet customer satisfaction. Consequently, we can conclude that design of any website cannot promise customer satisfaction there can be other aspects as well but it does impact directly. On the basis of this argument we can form a hypothesis:

H2a: The degree of user satisfaction directly and positively impact the website usabilityIn any relationship, satisfaction is related to the trust, trust increases with the satisfaction that a product or a business gives to a customer. Therefore, the level of trust is a result of the capability of a product/business to fulfill the desires of its customers [22].

Helson's theory of the degree of adaptation explains that the level of a customer satisfaction depends on the relation between his expectations and obtained outcomes. Johnson and Grayson [23] suggest that expectation is somehow linked with fear feelings of joy, and irritation related with the experience of any service or the contentment of any standards.

The client feels gratified when he/she observes the websites promises honesty, competence and benevolence.

Thus, as we claim that satisfaction can produce greater trust, we can formulate another hypothesis:

H2b: The degree of user satisfaction directly and positively impact the trust of website

\subsection{Trustworthiness}

As the internet services are getting more importance, many researchers have make an effort to find new ways to improve website trustworthiness and increase the customers intention to buy a product . Website trustworthiness may depend on buyer expertise in handling the website. E. Johnson [24], have described that the user's awareness of the website and required skills to handle website, reduces the probability of the customer changing to another product/website [25]. Though the price of surfing the net is very low and when that search could produce inexpensive products, users bound themselves within a few options and remain loyal with the websites with which they are familiar [26].

On the basis of above arguments we formulate the hypothesis:

H3a: The degree of user trustworthiness directly and positively impact the website usability

Greater customer satisfaction results in higher customer trustworthiness [27]. Precisely, if a customer trusts that the organization will accomplish the conditions and fulfill the promises that they have made then this relationship will last for a long time. Consequently, other alternatives available in the market will be less attractive. With the fulfillment of the expectations from the website, customer may intend to buy more in future; the customer may visit the website more often and spend more [28].

H3b: The degree of trustworthiness will lead to greater consumer satisfaction with the services offered by a website

\section{RESEARCH METHODOLOGY:}

Motivation behind this study was to get enough evidences to test the hypothesis that we formed. To get the data we have adopted the questionnaire from [4], along with it we have added few questions with it to know the details of participants, such as: their affiliations, their age bracket, and their preferred websites and on the basis of their preferred website selection they are asked to fill out the survey form.

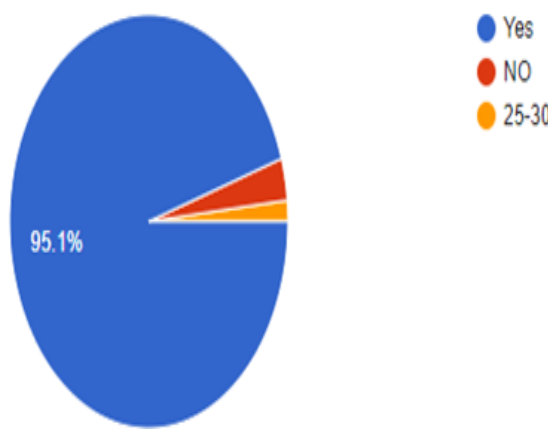

Figure 1: Have you ever visited an E-commerce site?

\subsection{Participants:}

To get potential surveyees we have done convenience sampling. Most of them were either undergraduate students or graduate students, it was also examined that participants of this survey are frequent users of E-commerce websites. Of those $1 / 5^{\text {th }}$ was females and $4 / 5^{\text {th }}$ was male, with a mean age of 22.8 years. Majority of them were 22-25 years old, while $1 / 4^{\text {th }}$ of them were between $18-22$ years old and $1 / 6^{\text {th }}$ of them were between $25-28$ years old. 


\subsection{Procedure:}

A survey form was created using Google forms and we asked participants to fill that form online, every participant was given enough time to think and fill the survey form. The form is consist of total 4 pages, first page is for demographics and other three are the actual questions, small pages were shown first to engage our participants. Participants had to rate each variable on the scale of 1 to $5 ; 1=$ Strongly Disagree, $2=$ Disagree, $3=$ Neutral, $4=$ Agree and $5=$ Strongly Agree.

\subsection{Evaluation Method:}

For analyzing data to get insightful results, we extracted data from Google forms in an excel sheet and then evaluated data Using SPSS. Different measures are applied on data; Test of Homogeneity of Variance, Anova and Individual means are compared to test the hypothesis. On the basis of those results hypothesis can be accepted or rejected.

\section{SURVEY RESULTS AND HYPOTHESIS TESTING:}

An extensive survey was done to get details about the participants and to get enough data to test hypothesis, below visualization provide details about each variable:

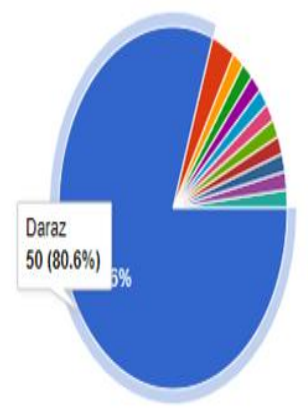

Daraz
Yayvo
Difierent Clothing brands
Ishopping.pk
Aliexpress
Daraz, The Protein Factory, The Wa...
Ali baba
Beechtree.pk
12 .

Figure 2: Which E-commerce site you have visited the most?

In figure 1 and 2, we can visualize almost $95.1 \%$ of the users have used an E-commerce site and figure 2 highlights which e-commerce site is been used by how much customers; Daraz.pk have majority users in this region.

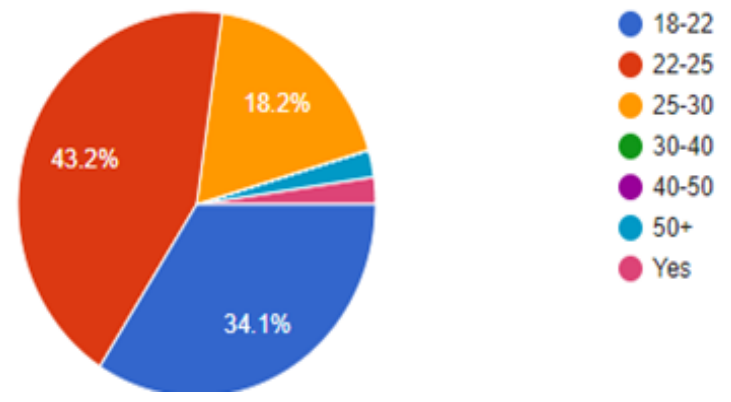

Figure 3: Age

From figure 3, we can visualize the participant's age, almost $43 \%$ of users have age between 22 to $25,34 \%$ of participants have age between $18-22$ and $18 \%$ of participants are between 25-30.

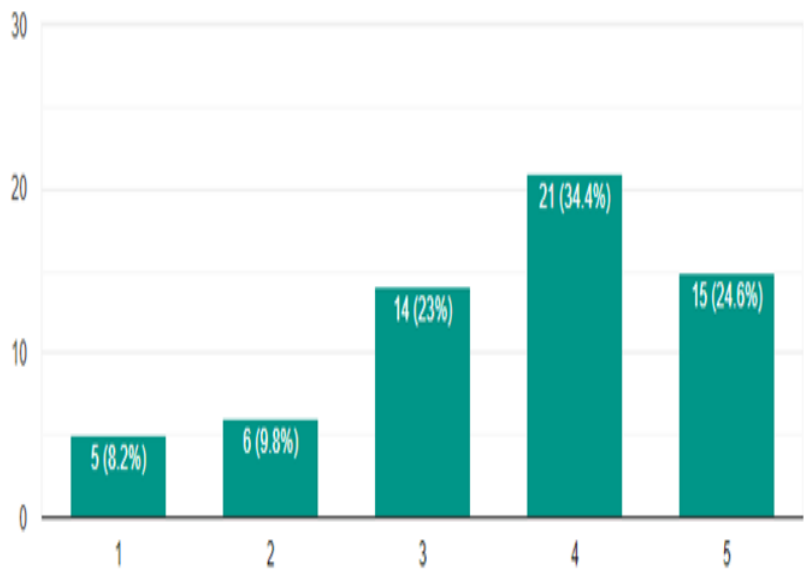

Figure 4: I visit this website more frequently than others of the same category.

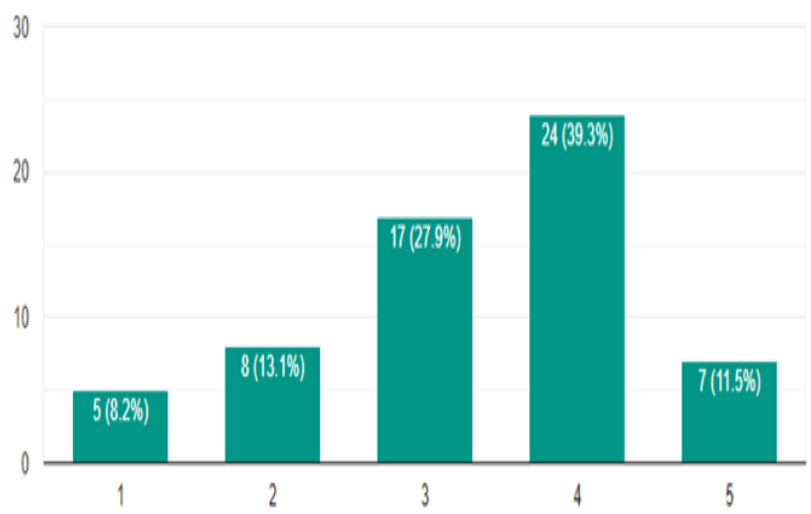

Figure 5: This is the website where I purchase the majority of the products and services in this Internet category

Figure 4 and Figure 5, gives a visualization of two variables of Trustworthiness. Figure 4 shows the frequency of website visits that a user has selected and majority of people have rated it positively.

Figure 5 illustrates the likelihood to purchase a majority of the product of same genre from this site. Most of the participants have rated it positively.

More visualization for Trustworthiness can be found in Annexure at the end of the research paper. 
30

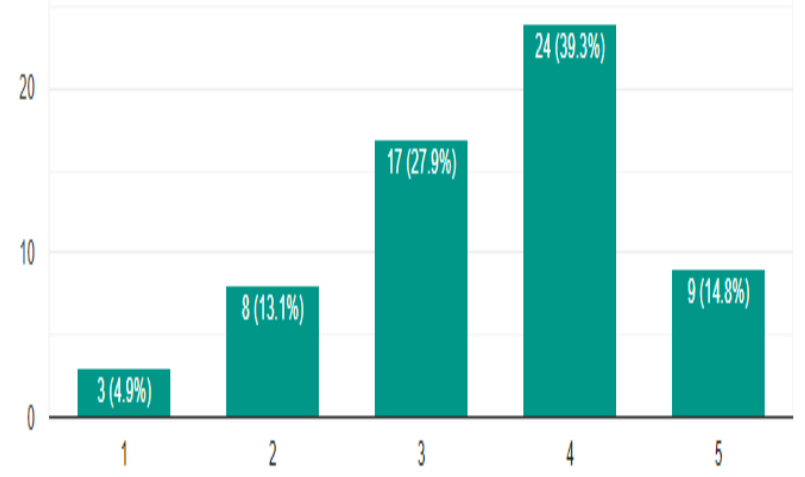

Figure 6: I think that I made the correct decision to use this website

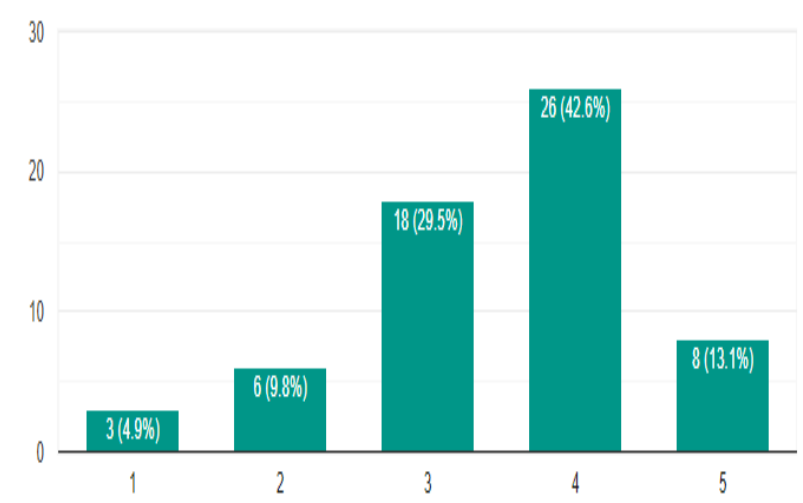

Figure 7: The experience that I have had with this website has been satisfactory

Figure 6 and figure 7 gives us the idea about some aspects that influence Satisfaction. Figure 6 illustrates the acceptance of participants that decision of using this website was a correct decision or not, results seem a bit higher in positive side. In figure 7 we can see the satisfaction rating of user experience, most of them seems satisfied.

More visualization for Satisfaction can be found in Annexure at the end of the research paper.

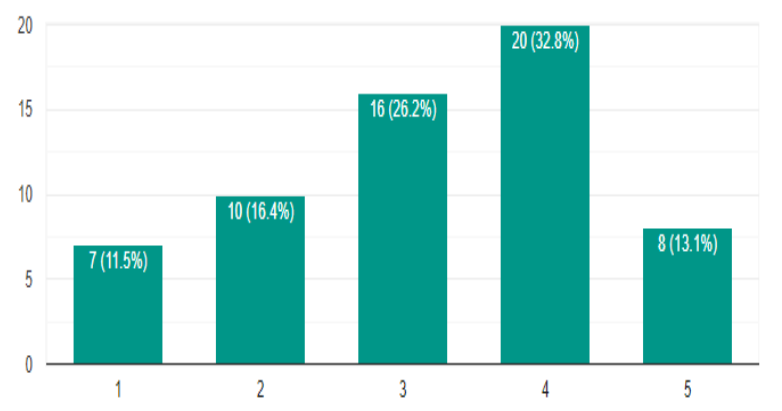

Figure 8: I think that the information offered by this site is sincere and honest

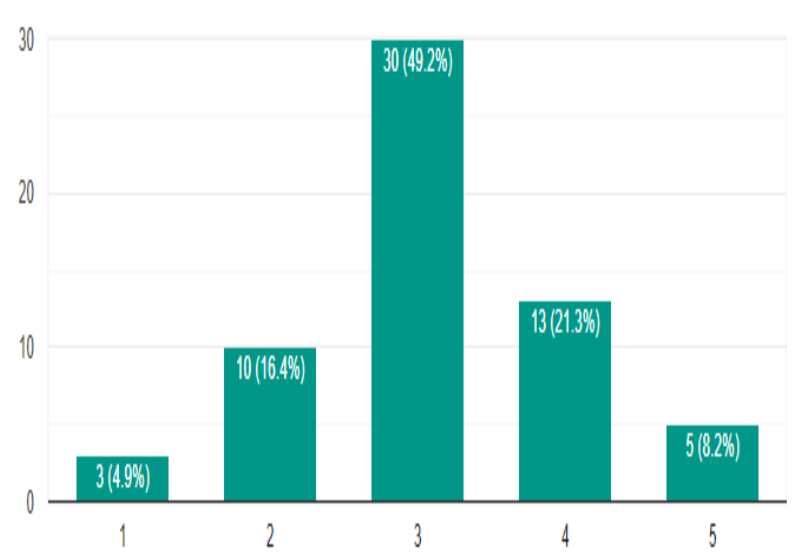

Figure 9: This website is characterized by the frankness and clarity of the services that it offers to the consumer.

Figure 8 and 9 illustrates the aspects that affect the trust. Figure 8 expresses the opinion of users about the sincerity and honesty of the website; most people think the information that a site offer is accurate. In figure 9, we can see the clarity of the services is ranked neutral by participants.

More visualization for Trust can be found in Annexure at the end of the research paper.

30

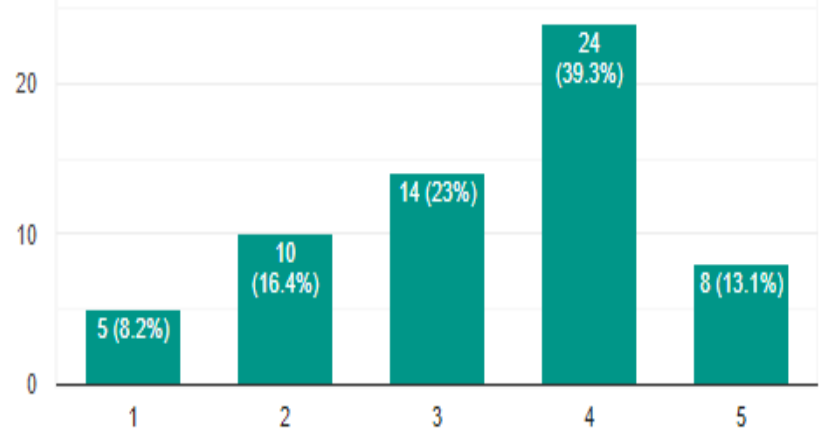

Figure 10: I think that this website usually fulfills the commitments it assumes

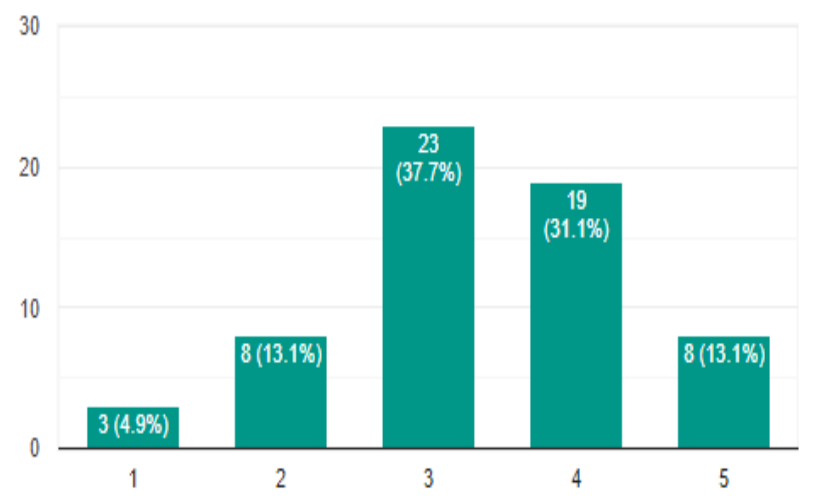

Figure 11: I think that this website is receptive to the needs of its users 
Figure10 and 11, gives visual information about some aspects of usability and participants opinions about it. Figure 10 illustrates that websites is fulfilling its commitments, more than a half people think that website fulfills it commitments.

Figure11gives a visualization about the fulfillments of user needs, major response is neutral whereas almost $2 / 5^{\text {th }}$ of population has given positive response.

More visualization for Usability can be found in Annexure at the end of the research paper

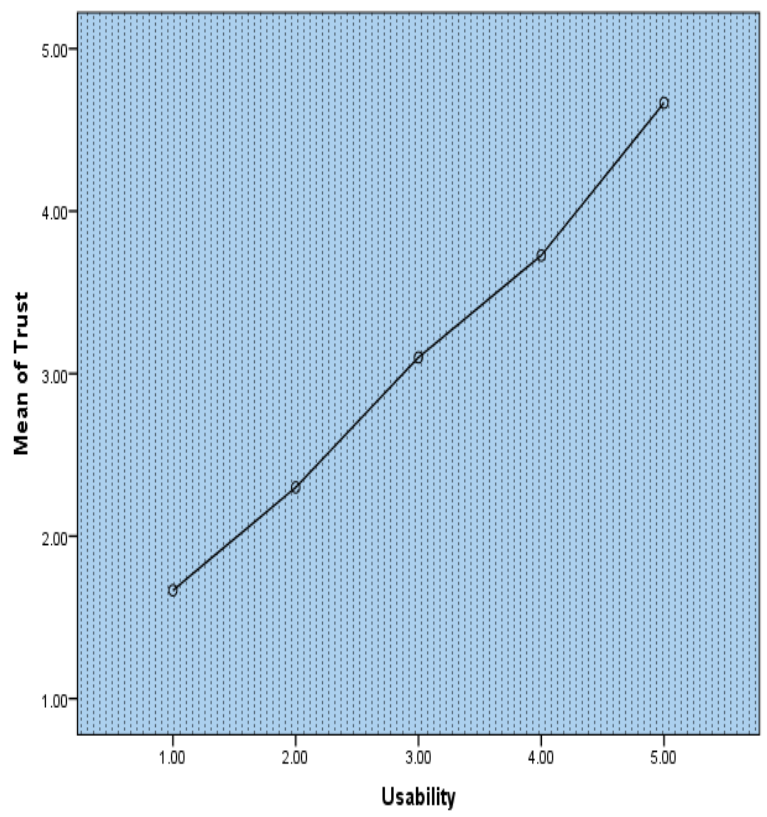

Figure 12: Trust

H1 The degree of trust directly and positively impact the website usability

From the figure1, we can easily conclude that, with increase in the website usability also affects its user's trust while using it. If the website is well designed user were willing to use it while putting trust on the site. As the website provide sincere and honestly information to user so there will be no information overloading which confuse the users, Moreover, website design were simple, easy to learn and remember as it provide relevant information to user and there is no irrelevant information in the website so the learnability of website increases which increase the memorability of the website which increase the trust of the website. And the above graph shows that trust increases with trust of the user on website so Hypothesis H1 is accepted.

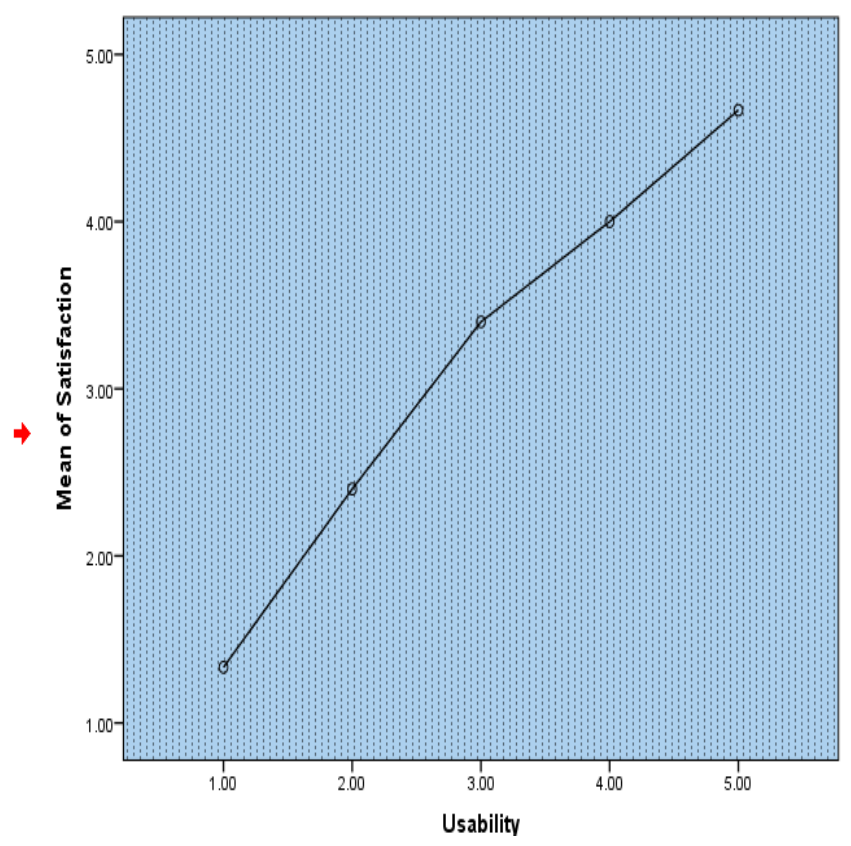

Figure 13: Satisfaction

H2a The degree of user satisfaction directly and positively impacts the website usability

$H 2 b$ The degree of user satisfaction directly and positively impacts the trust of website

From the Figure 2 a conclusion can made that better website usability increase the user satisfaction while using the website and trust of the users.as the user feel that alignment of website features highly impacts its usability and satisfaction while using it. Moreover, satisfaction and trust increase, when user can easily use the website with pleasurable experience. Hence hypothesis $\mathrm{H} 2 \mathrm{a}$ and $\mathrm{H} 2 \mathrm{~b}$ were accepted.

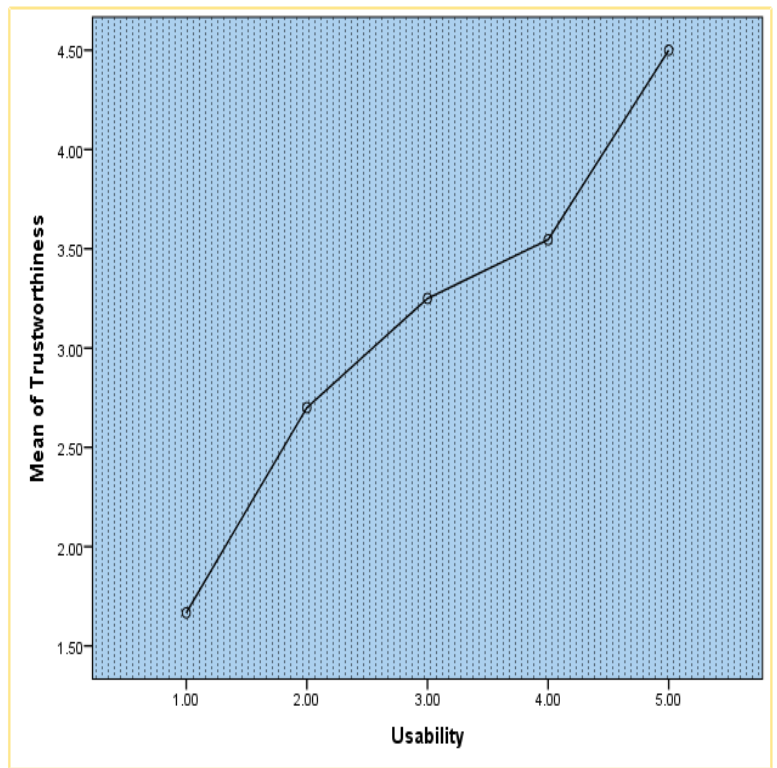

Figure 14: Trustworthiness 
H3a: The degree of user trustworthiness directly and positively impact the website usability

$H 3 b$ : The degree of trustworthiness will lead to greater consumer satisfaction with the services offered by a website

From the above figure 3 we can easily conclude with increase in the website usability also affects its user's trustworthiness which leads to greater user's satisfaction with the facilities offered by a website. As the user feel that the website is easy to use as all the information provided by the website was similar and mapped with user content. Moreover, user has frequently using the same kind of pattern, navigation and website so user can easily map those features as it saves user time. From the above graph we can conclude the H3a and H3b were accepted.

Test of Homogeneity of Variances

\begin{tabular}{|l|r|r|r|r|}
\hline & \multicolumn{1}{|c|}{$\begin{array}{l}\text { Levene } \\
\text { Statistic }\end{array}$} & \multicolumn{1}{c|}{ df1 } & \multicolumn{1}{c|}{ df2 } & \multicolumn{1}{c|}{ Sig. } \\
\hline Trust & 3.989 & 4 & 56 & .006 \\
Trustworthiness & .187 & 4 & 56 & .944 \\
Satisfaction & 12.322 & 4 & 56 & .000 \\
\hline
\end{tabular}

Figure 15: Test of Homogeneity

\begin{tabular}{|c|c|c|c|c|c|c|}
\hline \multicolumn{7}{|c|}{ ANOVA } \\
\hline & & $\begin{array}{l}\text { Sum of } \\
\text { Squares }\end{array}$ & df & Mean Square & $\mathrm{F}$ & Sig. \\
\hline \multirow[t]{3}{*}{ Trust } & Between Groups & 33.999 & 4 & \multirow{3}{*}{$\begin{array}{r}8.500 \\
.183\end{array}$} & \multirow[t]{3}{*}{46.375} & \multirow[t]{3}{*}{.000} \\
\hline & Within Groups & 10.264 & 56 & & & \\
\hline & Total & 44.262 & 60 & & & \\
\hline \multirow[t]{3}{*}{ Trustwothiness } & Between Groups & 21.611 & 4 & \multirow{3}{*}{$\begin{array}{r}5.403 \\
.348\end{array}$} & \multirow[t]{3}{*}{15.538} & \multirow[t]{3}{*}{.000} \\
\hline & Within Groups & 19.471 & 56 & & & \\
\hline & Total & 41.082 & 60 & & & \\
\hline \multirow[t]{3}{*}{ Satisfaction } & Between Groups & 40.013 & 4 & \multirow{3}{*}{$\begin{array}{r}10.003 \\
.200\end{array}$} & \multirow[t]{3}{*}{50.016} & \multirow[t]{3}{*}{.000} \\
\hline & Within Groups & 11.200 & 56 & & & \\
\hline & Total & 51.213 & 60 & & & \\
\hline
\end{tabular}

Figure 16: Anova

From result of the above table show the correlation between Trust, Trustworthiness and Satisfaction with respect to usability of the website. From the above table we can see the usability of the website highly depend upon the user trustworthiness as compare to trust and satisfaction, as the homogeneity sigma value of the trustworthiness is higher as compare to trust and satisfaction as shown in Table 1. And from Table 2 show that the $\mathrm{f}$ value is statically significant from .001, which mean variance between each group are statically different from each other and from all the factors $f$ value of trustworthiness is less as compare to both which show its dependent on the website usability as compare to other factors.

\section{CONCLUSION}

With extensive use of internet, website trustworthiness is a great challenge for developer and for researchers as well. A few factors that influence user trustworthiness could be perceived usability, trust and satisfaction provided by a website or a business. Different literatures suggest various definitions of these aspects and numerous research studies are been done as well to test those theories. In this study we have formed 5 hypotheses; a survey was filled by expert users and different measures were tested on SPSS, on the basis of those results hypotheses were tests.

All the hypotheses were accepted on the basis of results. So, we can conclude that trust, satisfaction and usability of a website have a huge impact on trustworthiness.

\section{REFERENCES}

[1] C. Shapiro and V. R. Hal, Informatin Rules: A STRATEGIC GUIDE TO THE NETWORK ECONOMY, H. B. S. Press, Ed.

[2] P. C. Verhoef and F. Langerak, "Possible determinants of consumers' adoption of electronic grocery," Journal of Retailing and Consumer Services, pp. 275-285, 2001.

[3] F. Selnes, "An Examination of the Effect of Product Performance on Brand Reputation, Satisfaction and Loyalty," European Journal of Marketing, vol. 27, no. 9, pp. 19-35.

[4] C. Flavian, M. Guinaliu and R. Gurrea, "Flavián, Carlos, Miguel Guinalíu, and Raquel Gurrea. "The role played by perceived usability, satisfaction and consumer trust on website loyalty," vol. 43, no. 1, pp. 1-14, January 2006.

[5] R. Anu, "The consumer benefits and problems in the electronic grocery store," Journal of Retailing and Consumer Services, vol. 9, no. 2, pp. 107-113, 2002.

[6] M. Naomi and E. Johnson, "Constructing Preferences Online: Can Web Pages Change What You Want?," Arbeitspapier, 2 Feb 1999.

[7] E. B. Kim and S. B. Eom, "Designing effective cyber store user interface," Industrial Management \& Data Systems, vol. 102, no. 5, pp. 241-251, 2002.

[8] R. Chandrasekaran and S. Ganapathy, "Key dimensions of business-to-consumer web sites," Information and Management, vol. 39, no. 6, pp. 457-465, 2002.

[9] "Ergonomic Requirements for office work with visual display terminal ( VDT)," INTERNATIONAL STANDARD, 05 March 1998. [Online]. Available: https://www.sis.se/api/document/preview/611299/. [Accessed 27 November 2018].

[10] J. Nielsen, Usability Engineering, San Francisco: Morgan Kaufmann Publishers Inc, 1993.

[11] S. Ganesan, "Determinants of Long-Term Orientation in Buyer-Seller Relationships," journal of Marketing, vol. 58, no. 2, pp. 1-19, April 1994.

[12] G. G. T and P. E. Murphy, "Ethical and legal foundations of relational marketing exchanges.," pp. 35-46, 1993.

[13] P. M. Doney and J. P. Cannon, "An Examination of the Nature of Trust in Buyer-Seller Relationships," Journal of Marketing, vol. 61, no. 2, pp. 35-51, 1997.

[14] L. R. E and T. Huston, "The dyadic trust scale: Toward understanding interpersonal trust in close relationships," Journal of Marriage and the Family, pp. 595-604, 1 August 1980.

[15] S. Mari and S. Helper, "Determinants of trust in supplier relations: Evidence from the automotive industry in Japan and the United States," Journal of Economic Behavior \& Organization, vol. 34, no. 3, pp. 387-417, 
1998.

[16] R. C. Mayer, J. H. Davis and F. D. Schoorman, "An integrative model of organizational trust," Academy of management review , vol. 20, no. 3, pp. 709-734, 1995.

[17] K. S. Coulter and R. A. Coulter, "Determinants of trust in a service provider: the moderating role of length of relationship," Journal of services marketing, vol. 16, no. 1, pp. 35-50, 2002.

[18] H. Wang and M. K. Lee, "Consumer privacy concerns about Internet marketing," Communications of the ACM , vol. 41, no. 3, pp. 63-70, 1998.

[19] E. F. Nicolas, "From interactions to transactions: designing the trust experience for business-to-consumer electronic commerce," 2003.

[20] E. Anderson and M. Sullivan, "The antecedents and consequences of customer satisfaction for firms," Management Science, vol. 12, no. 2, pp. 125-143, 1993.

[21] Q. Chen and R. Wigand, ".Com satisfaction and .Com dissatisfaction: one or two constructs?," Advances in Consumer Research, vol. 28, pp. 34-39, 2001.

\section{ANNEXURE}

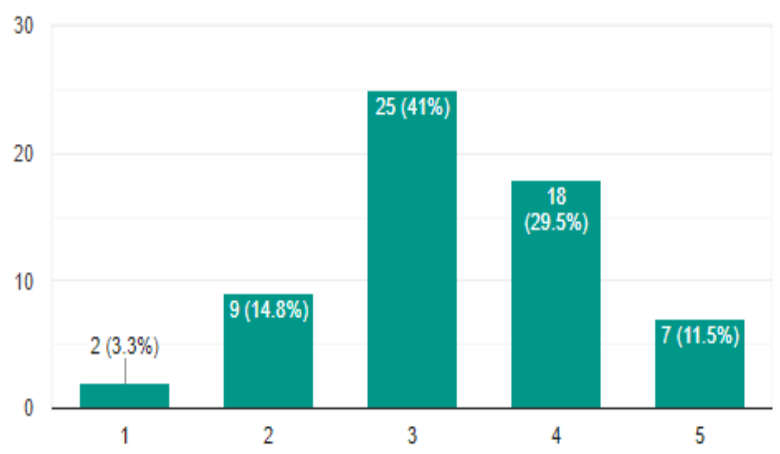

Figure 17:This is my favorite site for purchasing the products and services in this Internet category

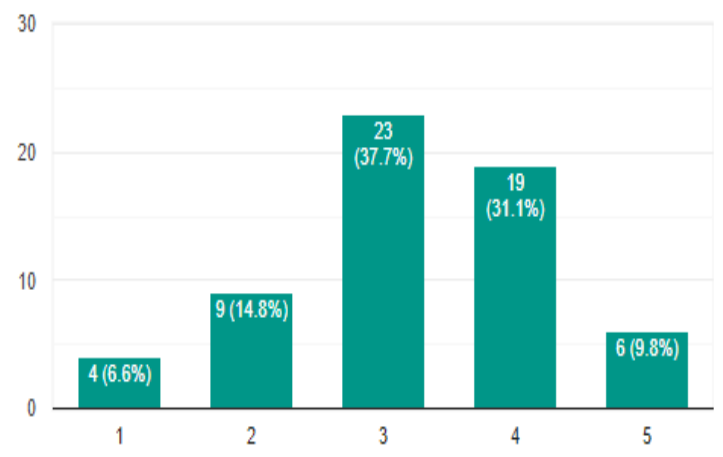

Figure 18: The frequency with which I visit other websites that offer similar products and services is much less
[22] F. Selnes, "Antecedents and consequences of trust and satisfaction in buyer-seller relationships," European Journal of Marketing, vol. 32, no. 3/4, pp. 305-322, 1998.

[23] D. johnson and K. Grayson, "Cognitive and affective trust in service relationshisp," Journal of Business Research, vol. 58, pp. 500-507, 2005.

[24] E.johnson, S. Bellman and G. Lohse, "What makes a website 'sticky'? Cognitive lock-in and the power law of practice," Columbia School of Business, 2000.

[25] L.Adamic and B. Huberman, "The nature of markets in the World Web," Quarterly Journal of Electronic Commerce, vol. 1, pp. 5-12, 2000.

[26] J. Figueiredo, "Finding sustainable profitability in electronic commerce," pp. 41-52.

[27] S.Yoon and J. Kim, "An empirical validation of a loyalty model based on expectation disconfirmation," vol. 2, pp. 120-126, 2000.

[28] J. Littlefield, Y. Bao and D. Cook, "Internet real estate information: are home purchasers paying attention to it?," vol. 17, no. 7, pp. 575-590, 2000.

30

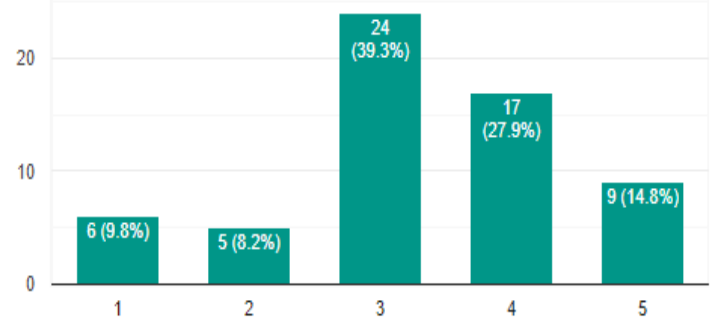

Figure 19:I don't usually purchase products and services from this category from other websites

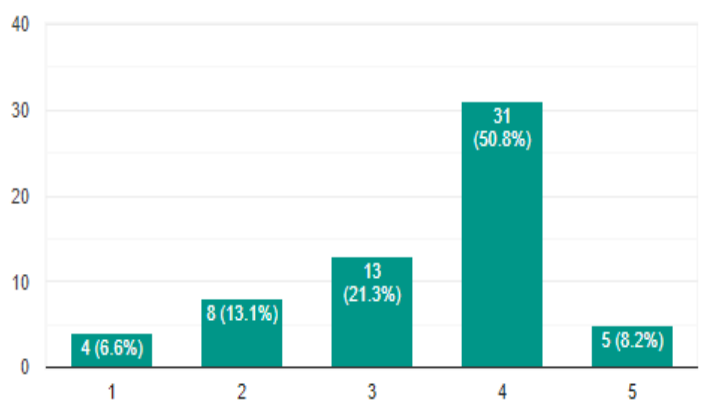

Figure 20:In general terms, I am satisfied with the way that this website has carried out transactions 


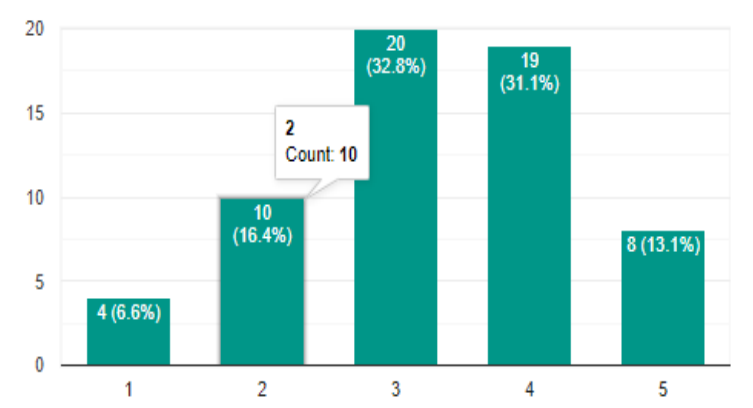

Figure 21:In general, I am satisfied with the service I have received from the website

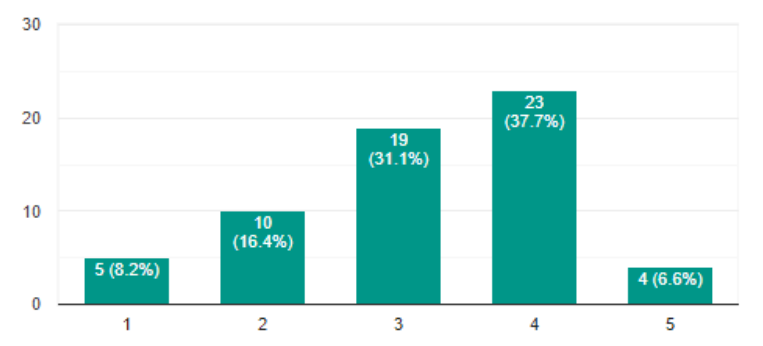

Figure 22:I think that the advice and recommendations given on this website are made in search of mutual benefit

30

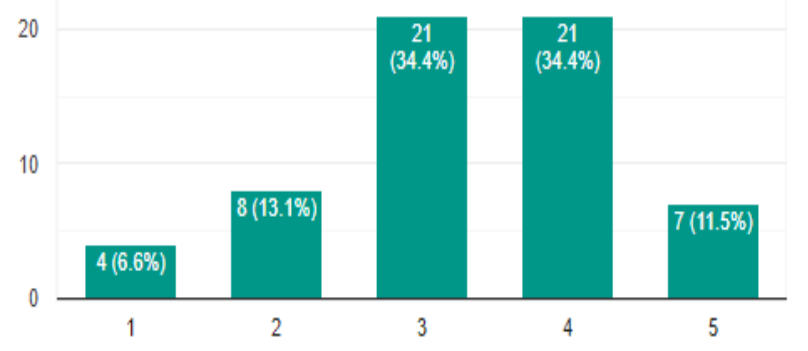

Figure 23:I think that this website is concerned with the present and future interests of its users

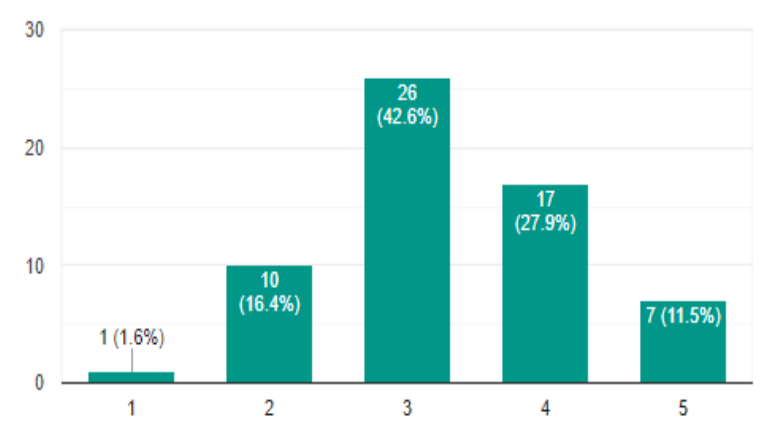

Figure 24:I think that this website would not do anything intentional that would prejudice the user
30

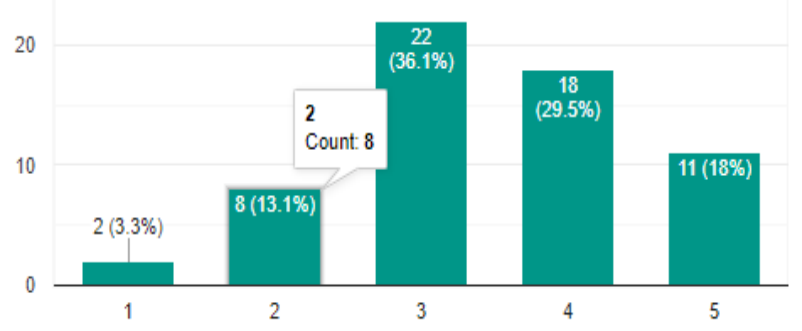

Figure 25:I think that this website has sufficient experience in the marketing of the products and services that it offers

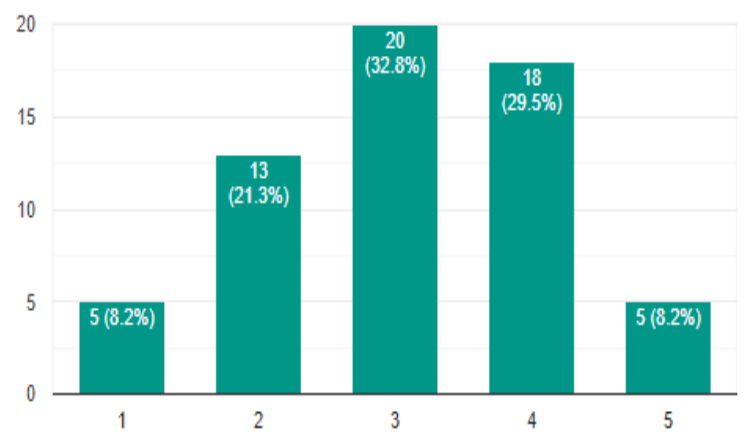

Figure 26:I think I can have confidence in the promises that this website makes

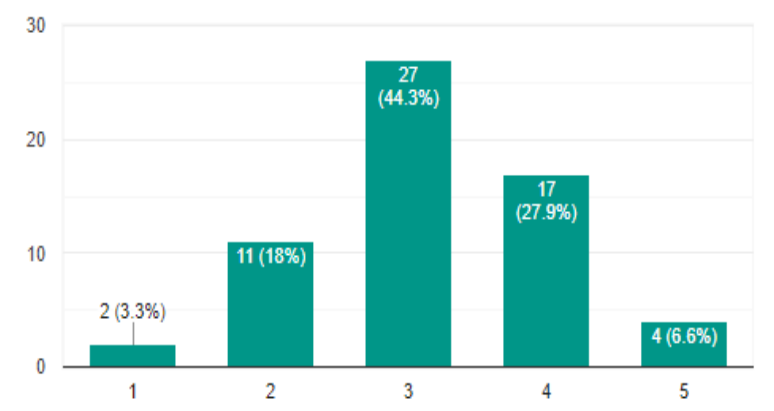

Figure 27:I think that this website takes into account the repercussions that their actions could have on the consumer

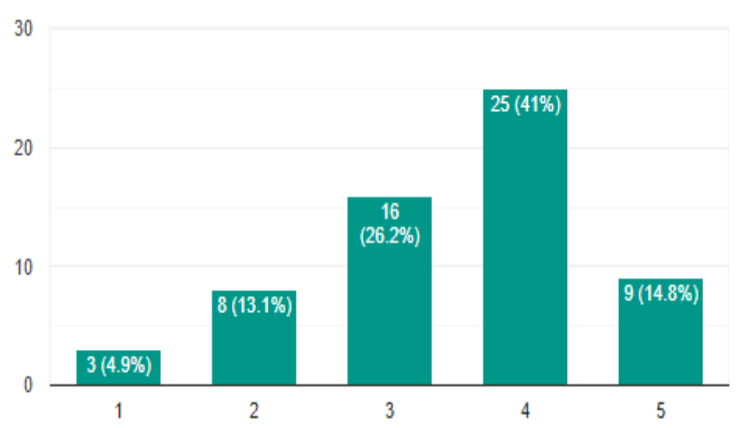

Figure 28:I think that this website has the necessary abilities to carry out its work 